\title{
Media Optimization for Exopolysaccharide Producing Klebsiella pneumoniae KU215681 under Varying Cultural Conditions
}

\author{
T. Sivakumar ${ }^{*}$ T. Shankar, V. Thangapandian, S. Mahendran \\ Department of Microbiology, Ayya Nadar Janaki Ammal College (Autonomous), India
}

Copyright $(2016$ by authors, all rights reserved. Authors agree that this article remains permanently open access under the terms of the Creative Commons Attribution License 4.0 International License

\begin{abstract}
The soil samples were collected from Western Ghats. It was processed as per microbiological procedure. The observations in terms of morphological, physiological, biochemical and genetical were made for identifications of selected exopolysaccharides producing bacteria. The selected isolate was confirmed as Klebsiella pneumoniae by $16 \mathrm{~S}$ rRNA sequences. It was taken up for further studies to ascertain the various cultural conditions for exopolysaccharide production. The EPS (exopolysaccharides) producing ability was evaluated by nutritional defined media. The data obtained reveals that the $\mathrm{pH}$, temperature, carbon, nitrogen, aminoacids surfactants, metal ions conditions had the most significant influences. Among the various nutritional sources of interactive effects the maximum EPS production was recorded at $\mathrm{pH} 7.00$ (1.58 $\pm 0.0096)$, Temperature at $37^{\circ} \mathrm{C}$, Jaggery $(1.37 \pm 0.003)$, Tryptone $(1.56 \pm 0.012)$, Ferric chloride $(1.98 \pm 0.02)$, Glutamine $(2.13 \pm 0.067)$, Polyethylene glycol $(0.79 \pm$ $0.043)$.
\end{abstract}

Keywords EPS, Media Optimization, 16S rRNA, Klebsiella pneumoniae

\section{Introduction}

The past few decades, several microbes have been investigated for the production of exopolysaccharides using whey or lactose as fermentation substrate [1]. Xanthan and gellan gums are examples of fighting fit acknowledged bacterial exopolysaccharides that have significant industrial importance. Apart from bacteria, attempts have been made to produce exopolysaccharides from submerged fungi cultures [2]. Over the past three decades, attempts have been made to improve the utilization of whey by using it as a fermentation substrate for producing value added products such as ethanol and microbial exopolysaccharides. Research on producing commercial bacterial gumsusing whey or lactose based media, with the goal of improving whey utilization, have been done with little success. Isolate lactose metabolizing exopolysaccharide producing microorganisms have been made by under optimized conditions, Klebsiella oxytoca produced copious amounts of exopolysaccharide, $15 \mathrm{~g} / \mathrm{l}$, that had very high apparent viscosity. It has been reported that the location of genes for expolysaccharide production in this $K$. oxytocaare plasmid encoded [3] thus prompting favorable recombinant DNA technology manipulation with lactic acid bacteria. This is paramount because several researches have shown that lactic acid producing bacteria produces very low exopolysaccharides yields $[4,5]$.

In the natural environment, exopolysaccharide (EPSs) is generally hetero polymeric (made of different monomeric units), non-sugar components like uronic acid, methyl esters, sulphates, pyruvates, proteins, nucleic acids and lipids. EPS also contain divalent metal cations that act as ionic bridges linking adjacent polysaccharide chains Many microorganisms like bacteria, fungi and actinomycetes are produce high molecular weight, hydrated polymeric compounds called exopolysaccharides (EPS) during their lifecycle. Many bacterial cultures produce different types of EPS during its life-cycle. For example, most bacteria produce capsular form of EPS during the exponential growth phase and slime type EPS during the stationary growth phase[6]. EPS may exist as capsules, sheaths, slimes (loosely attached to the cell wall), apical pads or mesh like fibrils in the natural environment. Capsules are tightly bound to the cell wall by non-covalent linages whereas sheaths are linear EPS containing structures surrounding chain of cells. Slime layer is a less organised form of capsule or sheath that diffuses into the surrounding environment. The presence of side linkages and organic molecules influence the overall charge, stability, binding capacity, rheology and solubility of the polymer [7].

Most microorganisms produce exopolysacccharide either for attachment to substratum (adhesion), formation of micro-consortium/biofilms or binding to other particulate matter (cohesion or aggregation). EPS produced for 
attachment by microorganisms may influence biofouling by conditioning the substratum. Other functions like gliding motility, protection against osmotic shock, predation, desiccation and detoxification of toxic compounds, nutrient sequestering, chelation of metals, horizontal transfer of genetic material have also been attributed to microbial EPS[8. 9].The purpose of this research was to determine the properties of the exopolysaccharides produced by Klebsiella pneumonia $\mathrm{ku} 215681$, so that its media optimization for EPS production can be ascertained.

\section{Material and Methods}

Soil sample was collected from Western Ghats near Tamilnadu (North Latitude, $11^{\circ} 00^{\prime}$ and $12^{\circ} 00 \mathrm{~N}$, East Longitude, $77^{\circ} 28^{\prime}$ and $\left.78^{\circ} 50^{\prime}\right)$ and Kerala $\left(77^{\circ} 15^{\prime}\right.$ and $77^{\circ}$ $36^{\prime}$ East latitude \& $8^{\circ} 03^{\prime}$ and $8^{\circ} 35^{\prime}$ North Latitude). Isolates were obtained by serial dilution plating on nutrient agar medium. Total of10 different colonies were isolated and the exopolysaccharide producing bacteria were screened based on their morphological characters, mucous and ropy appearances.

\subsection{Identification and Biochemical Characterization of Bacterium}

\subsubsection{Motility Test}

The motility test was carried out by hanging drop method. A loop full of overnight bacterial cell was transferred on the center of the coverslip. The cavity slide was placed over the coverslip and turned to prepare a hanging drop. It was examined under light microscope and the non-motility of bacterial cells was observed.

\subsubsection{Indole Production Test}

Indole production test is used to test whether the organism can oxidize tryptophan for the synthesis of indole compounds. The isolate was inoculated into appropriate test tubes and one tube serves as control. Incubate tubes for 24 hours at $37^{\circ} \mathrm{C}$. Culture producing a cherry red color following addition of Kovac's reagent is indole positive. The absence of red coloration indicates a negative reaction.

\subsubsection{Methyl Red Test}

The methyl red test is employed to detect the ability of microorganisms to oxidize glucose with the production of high concentration of acid and acid products. The isolate was inoculated into test tubes containing MR-VP broth and one tube serves as control. Tubes were incubated for 24 hours at $37^{\circ} \mathrm{C}$. The methyl red indicator in the $\mathrm{pH}$ range of 4 will turn red, which is indicative of a positive test. If the indicators turn yellow, it is a negative test.

\subsubsection{Voges-Proskauer Test}

This test is used to differentiate the capacity of the microorganisms to produce some non-acidic (or) neutral end product such as acetyl methyl carbinol (or) 2,3butanol. The isolate was inoculated into test tubes containing MR-VP broth and one tube serves as control incubate tubes for 24 hours at $37^{\circ} \mathrm{C}$. Development of deep rose color in the culture 15 minutes following addition of Barrit's reagent is the indication of positive result. The absence of rose colouration is a negative result.

\subsubsection{Citrate Utilization Test}

The culture was inoculated in Simmon's citrate agar and incubated at $37^{\circ} \mathrm{C}$ for 24 hours. This medium contains bromothymol blue (green at acidic $\mathrm{pH}$ around 6.0 and changes to blue at alkaline $\mathrm{pH}$ around 7.6). Uninoculated simmon's citrate agar has a $\mathrm{pH}$ of 6.9 , with light green colour. Growth of bacteria in the media leads to the development of a Prussian blue color.

\subsubsection{Catalase Test}

The isolate was transferred to the center of the slide and 1-2 drops of hydrogen peroxide was added. Catalase positive organisms were indicated by strong bubble formation by breaking $\mathrm{H}_{2} \mathrm{O}_{2}$. Catalase negative organism was indicated by no bubble formation.

\subsubsection{Oxidase Test}

A clean glass slide was taken and a drop of culture suspension was placed on it. To the culture few drops of p-amino dimethylaniline oxalate was added. Oxidase positive microorganisms were indicated by blue color formation. Oxidase negative organisms were indicated by no color formation.

\subsubsection{Hydrogen Sulfide Production}

Experimental organisms were inoculated into appropriately labelled tubes by means of a stab and steak inoculations. The tubes without organism served as control. All the cultures were incubated for 24 hours at $37^{\circ} \mathrm{C}$. Development of black color in the medium was positive for $\mathrm{H}_{2} \mathrm{~S}$ production. Absence of the black color was evidence of a negative reaction.

\subsubsection{Nitrate Reduction Test}

The culture was inoculated into nitrate broth and incubated at $37^{\circ} \mathrm{C}$ for 24 hours. After incubation few drops of naphthalamine and sulphanic acid was added and mixed well. Positive result is indicated by red color formation.

\subsubsection{Urease Test}

Urea base medium was prepared and sterilized. The urea was added after sterilization and slant was prepared. The loop full of inoculums was streaked on the urease slants and they detected for urease production by utilization of urea with respective to production by utilization of urea with respective to production of alkaline conditions indicated by color change. 


\subsection{Identification of Bacteria by $16 \mathrm{~S}$ rRNA Gene Sequencing Analysis}

\subsubsection{Genomic DNA Isolation from Isolate}

The isolated bacterial strain was grown in $25 \mathrm{ml} \mathrm{LB}$ broth overnight at $35^{\circ} \mathrm{C}$. The culture was spin at $5000 \mathrm{rpm}$ for $5 \mathrm{~min}$. The pellet was resuspended in $400 \mu 1$ of sucrose TE buffer (Tris EDTA). Lysozyme was added to a final concentration of $8 \mathrm{mg} / \mathrm{ml}$ and incubated for 1 hour at $35^{\circ} \mathrm{C}$. To this tube, $100 \mu 1$ of $0.5 \mathrm{M}$ EDTA (pH 8.0), $60 \mu 1$ of SDS and $3 \mu 1$ of proteinase $-\mathrm{K}(20 \mathrm{mg} / \mathrm{ml})$ were added and incubated at $55^{\circ} \mathrm{C}$. After incubation, they were centrifuged at $7000 \mathrm{rpm}$ for $3 \mathrm{~min}$ and then the supernatant were extracted twice with phenol: chloroform (1:10 and again with chloroform: isoamyl alcohol (24:1). It was precipitated with ethanol. The DNA pellet was resuspended in sterile buffer.

\subsubsection{Amplification of $16 \mathrm{~S}$ rRNA Gene Sequence}

Bacterial 16S rDNA was amplified from the extracted genomic DNA using the following universal eubacterial 16S rRNA primers: forward primer 5, AGAGTTTGATCCTGGCTCAG 3' and reverse primer 5', ACGGCTACCTTGTTACGACTT 3'. Polymerase chain reaction was performed in a typical reaction mixture was $2 \mu 1$ of template DNA and $1.5 \mu 1$ of forward primer, $1.5 \mu 1$ of reverse primer, $10 \mu 1$ of $2 \mathrm{X}$ PCR master mixes and $5 \mu 1$ of nuclease free water for $20 \mu 1$ reaction. The reaction was performed with an initial denaturation at $94^{\circ} \mathrm{C}$ for 2 minutes. 30 cycles of denaturation at $94^{\circ} \mathrm{C}$ for 45 seconds, annealing at $56^{\circ}$ for 1 minute, extension at $72^{\circ} \mathrm{C}$ for 1 minute 30 seconds followed by final extension at $72^{\circ} \mathrm{C}$ for 5 minutes and hold at $4{ }^{\circ} \mathrm{C}$. The amplification of $16 \mathrm{~S}$ rRNA gene was confirmed by running the amplification product in $1 \%$ agarose gel electrophoresis.

\subsubsection{Bacterial EPS Quantification}

After 72 hours of incubation, basal medium were centrifuged at 5000rpm for $20 \mathrm{~min}$. The EPS was then precipitated from the supernatant by addition of equal amount of carbinol. The mixture were agitated with addition of methanol to prevent local high concentration of the precipitate and left over night at $4^{\circ} \mathrm{C}$ and centrifuged at 7000 rpm for 20 mins. After centrifugation the precipitate was collected in a petri plate and dried at $60^{\circ} \mathrm{C}[10]$.

\subsection{Media Optimization of Physiological Factors for EPS}

\subsubsection{Effect of Different $\mathrm{pH}$}

Different $\mathrm{pH}(3,4,5.6,7,8$ and 9$)$ were adjusted into the production medium to determine the effect of $\mathrm{pH}$ on bacterial growth for EPS production. Growth of the organism was determined by optical density measured at 600 $\mathrm{nm}$ for media optimization of physiological factors for EPS[11].

\subsubsection{Effect of Different Temperature}

Different temperatures $\left(10,20,30,40,50\right.$ and $\left.60^{\circ} \mathrm{C}\right)$ were used to prepare production medium to determine the effect of temperature on bacterial growth and EPS production. Growth of the organism was determined by optical density measured at $600 \mathrm{~nm}$ for media optimization of physiological factors for EPS [11].

\subsubsection{Effect of Different Incubation Time}

In the production medium different incubation time (24, $48,72,96$ and 120) hours were incubated to determine the effect of incubation time on bacterial growth and EPS production. Growth of the organism was determined by optical density measured at $600 \mathrm{~nm}$ for media optimization of physiological factors for EPS [11].

\subsubsection{Effects of Different Carbon Sources}

Different carbon sources at $1 \%$ concentration (Dextrose, Jaggery, Sucrose, Maltose, Lactose and Molasses) were introduced to the production medium to determine the effect of carbon dose on EPS production. Growth of the organism was determined by optical density measured at $600 \mathrm{~nm}$ for media optimization of physiological factors for EPS [11].

\subsubsection{Effects of Nitrogen Sources}

Different nitrogen sources at $0.5 \%$ concentration (Urea, Tryptone, Glycine, Ammonium sulphate, Ammonium chloride and Ammonium carbonate) were introduced into the production medium individually to determine the effect of nitrogen source on microbial growth and EPS production. Growth of the organism was determined by optical density measured at $600 \mathrm{~nm}$ for media optimization of physiological factors for EPS.

\subsubsection{Effects of Metal Ions}

Different metal ions at $0.02 \%$ concentration (Mercuric choride, Manganese sulphate, Ferric chloride, Zinc sulphate, Copper sulphate, Calcium chloride, Disodium hydrogen phosphate, Mercuric oxide and ferrous sulphate) were introduced into the production medium individually to determine the effect of metal ions on microbial growth and EPS production. Growth of the organism was determined by optical density measured at $600 \mathrm{~nm}$ for media optimization of physiological factors for EPS.

\subsubsection{Effects of Amino Acids}

Different amino acids at $0.2 \%$ concentration (Glycine, Glutamine, Cysteine, Alanine, and Methionine) were introduced into the production medium individually to determine the effect of amino acids on microbial growth and EPS production. Growth of the organism was determined by optical density measured at $600 \mathrm{~nm}$ for media optimization of physiological factors for EPS [12].

\subsubsection{Effects of Surfactants}

Different surfactants at $0.2 \%$ concentration (SDS, PEG, Tween 80 and Triton $X$ 100) were introduced into the 
production medium individually to determine the effect of surfactants on microbial growth and EPS production. Growth of the organism was determined by optical density measured at $600 \mathrm{~nm}$ for media optimization of physiological factors for EPS [13].

\section{Results}

\subsection{Isolation and Selection of Selected Bacterium}

Soil samples were taken from Western Ghats area for this study. The samples were serially diluted and plated for screening of efficient EPS producing microorganism. After $24 \mathrm{hrs}$ of incubation, the plates were kept at $37^{\circ} \mathrm{C}$. Selected strain which exhibited EPS production on basal medium after further confirmation was used for further studies. The selected strain was identified by various physical, biochemical and molecular characters. This strain exhibited Gram negative, rod shaped and non-motile bacteria. According to Bergey's manual of Determinative Bacteriology, the selected microbes were identified as Klebsiella sp. All the carbon utilizing and biochemical studies were performed and results were presented (Table. 1.).

Table 1. Morphological and biochemical characteristics of Klebsiella sp.

\begin{tabular}{|c|c|}
\hline Colony morphology & Observation \\
\hline Gram staining & Gram negative, rod \\
\hline Motility & Non Motile \\
\hline Biochemical Characters & \\
\hline Indole production test & Negative \\
\hline Methyl red & Negative \\
\hline VogesProskauer & Negative \\
\hline Citrate utilisation test & Positive \\
\hline Catalase test & Positive \\
\hline Oxidase test & Negative \\
\hline Nitrate utilisation test & Negative \\
\hline Hydrogen sulphide production & Negative \\
\hline
\end{tabular}

\subsection{Identification of Strains based on 16S rRNA Sequencing}

The 16S rRNA gene of the Klebsiella $s p$. was amplified using Polymerase Chain Reaction (PCR) with the help of $16 \mathrm{~S}$ rRNA Universal primers. The sequences were compared against 16S rRNA sequences available in the RDP database (http: 11rdp (me. msu. edu/). The sequence analysis revealed that the strains were phylogenetically closely related to the genus Klebsiella. Blast analysis of the 16S rRNA sequence of isolate revealed that the selected isolates showed maximum similarity of $98 \%$ with Klebsiella pneumonia

The Phylogenetic relationship was obtained using neighbor joining by pair wise comparison among the $16 \mathrm{~S}$ rRNA gene sequence of selected isolates with species. The dendrogram was constructed for their Phylogenetic relationship and it revealed that the isolate
Klebsiellapneumoniaewas distinctly placed under separate clusters. The 16S rRNA gene sequences of the isolates had been submitted to the NCBI Genbank and accession number Klebsiella pneumoniae ku215681.

\subsection{Media Optimization of Cultural Conditions for Eps Production by Klebsiella pneumoniae ku215681}

\subsubsection{Effect of $\mathrm{pH}$}

EPS production by the isolate isolated from Western Ghats soil was adjusted using various cultural conditions. The EPS production was assayed after 72 hours of incubation at $30^{\circ} \mathrm{C}$ under various $\mathrm{pH}$. Maximum EPS production was recorded at $\mathrm{pH} 7.00(1.58 \pm 0.0096)$ next to that maximum EPS production was observed at $\mathrm{pH} 6.00$ $(1.245 \pm 0.021)$. Minimum EPS production was recorded at pH $3.00(0.879 \pm 0.0141)$ (Fig. 1$)$.

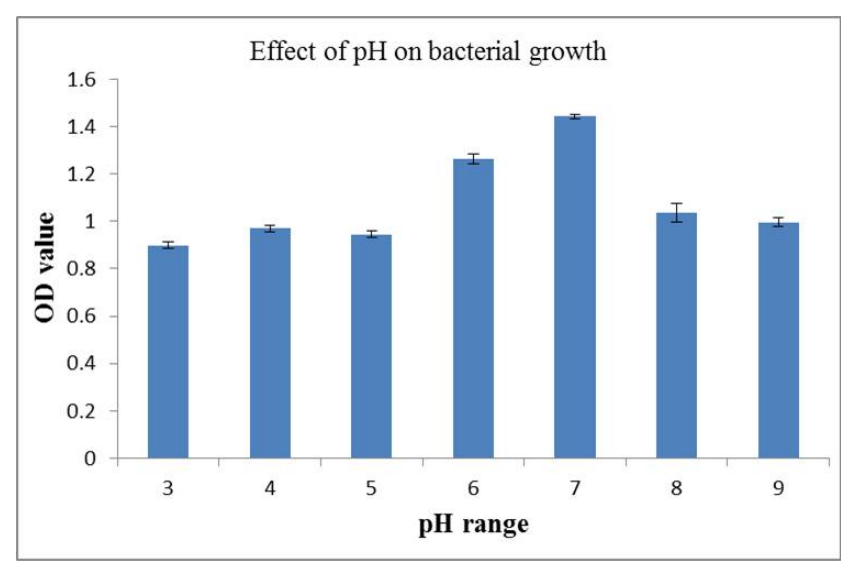

Figure 1. Effect of $\mathrm{pH}$ on EPS production

\subsubsection{Effect of Temperature}

Among the various temperature tested the maximum EPS production was obtained at $30^{\circ} \mathrm{C}(1.661 \pm 0.028)$, followed by this at $40^{\circ} \mathrm{C}(1.249 \pm 0.007)$ was the second best temperature on EPS production. On the other hand, the minimum amount of EPS production was observed at $10^{\circ} \mathrm{C}$ $(0.952 \pm 0.125$ OD) (Fig.2).

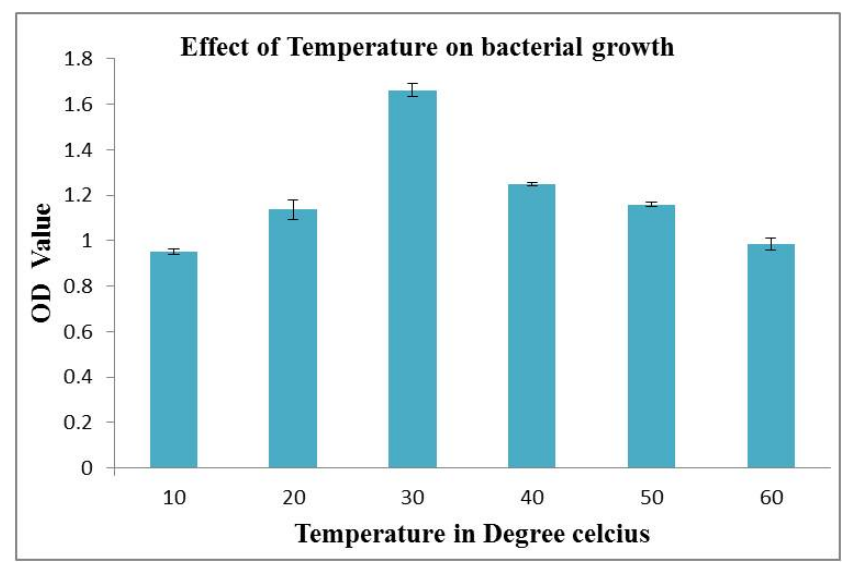

Figure 2. Effect of temperature on EPS production 


\subsubsection{Effect of Carbon Source}

The effect of carbon source on EPS production by Klebsiella pneumoniae KU215681after 72 hours incubation at $30^{\circ} \mathrm{C}$. Here the maximum EPS production was observed in Jaggery $(1.37 \pm 0.003)$ supplemented medium. The minimum EPS production was observed in Lactose (1.008 \pm 0.005 ) provided medium (Fig. 3).

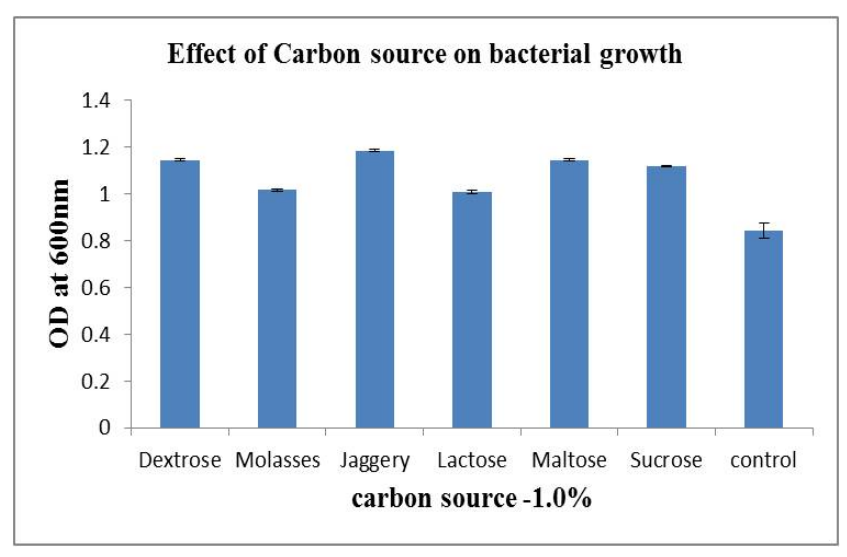

Figure 3. Effect of carbon source

\subsubsection{Effect of Nitrogen Source}

The effect of different nitrogen sourceson EPS production after 72 hours of incubation period at $30^{\circ} \mathrm{C}$ showed maximum amount of EPS production on Tryptone (1.56 \pm 0.012) supplemented medium and minimum amount of EPS production in urea $(0.125 \pm 0.017)$ (Fig.4).

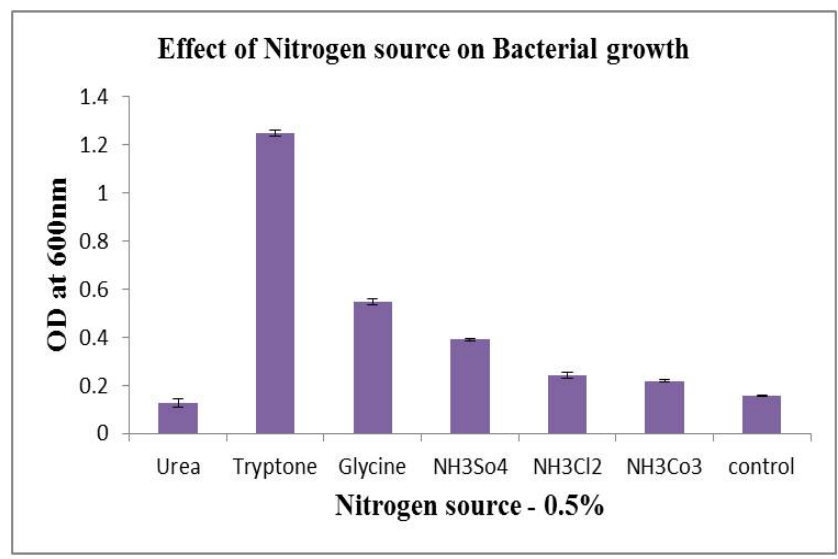

Figure 4. Effect of nitrogen source

\subsubsection{Effect of Metal Ions}

Among the tested metal ions, the maximum amount of EPS production was observed in Ferric chloride $(1.98 \pm$ 0.022 ) supplemented medium. Followed by this, magnesium oxide was the second best metal ions on EPS production $(1.137 \pm 0.013)$, whereas the minimum amount of EPS production was observed in zinc sulphate $(0.793 \pm$ 0.004)(Fig.5).

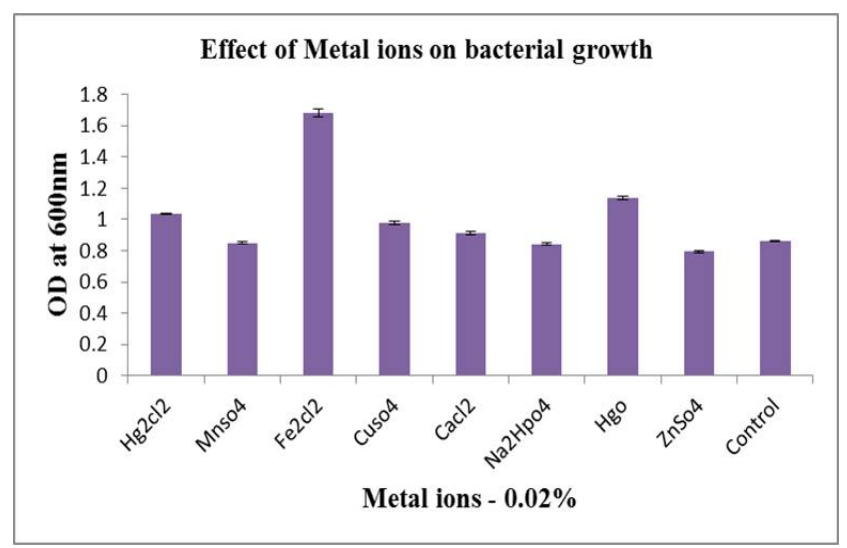

Figure 5. Effect of metal ions on EPS production

\subsubsection{Effect of Amino Acids}

The effect of various aminoacids on EPS production after 72 hours of incubation period at $30^{\circ} \mathrm{C}$ showed maximum amount of EPS production observed in Glutamine (2.13 \pm $0.067)$ supplemented medium. Followed by this Alanine $(2.036 \pm 0.023)$ was second best aminoacids in EPS production, whereas the minimum amount of EPS productin was observed in Cysteine (1.065 \pm 0.041$)$ (Fig.6). The glutamine also siginificant effect for EPS by the selected organism.

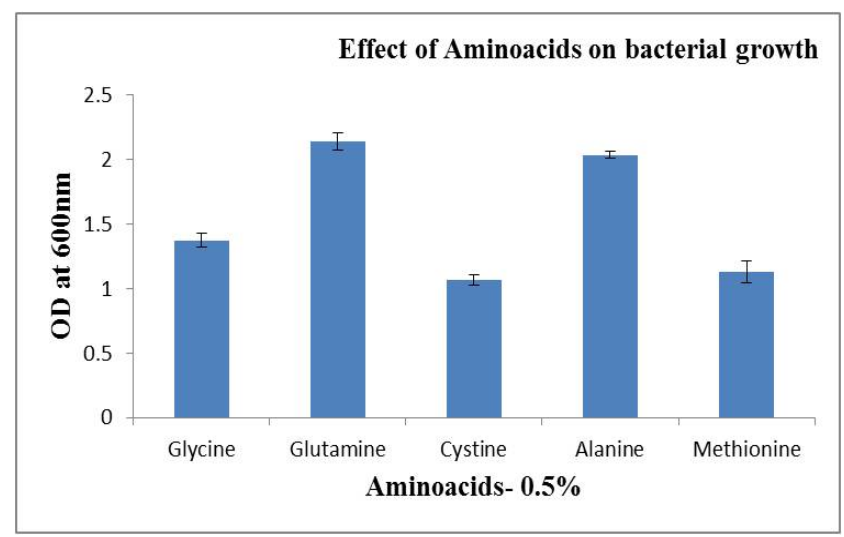

Figure 6. Effect of aminoacids

\subsubsection{Effect of Surfactants}

The effects of different kinds of surfactants was tested on EPS production after 72 hours of incubation period at $30^{\circ} \mathrm{C}$. Among the tested surfactants, the maximum amount of EPS production was observed in polyethyleneglycol $(0.79 \pm$ $0.043)$ supplemented medium. Followed by this Tween- 80 $(0.667 \pm 0.033)$ was second best surfactant in EPS production, whereas the minimum amount of EPS production was observed in SDS $(0.0633 \pm 0.0313)$. By the presence of PEG in the medium, the EPS producytion was highger than others(Fig.7). 


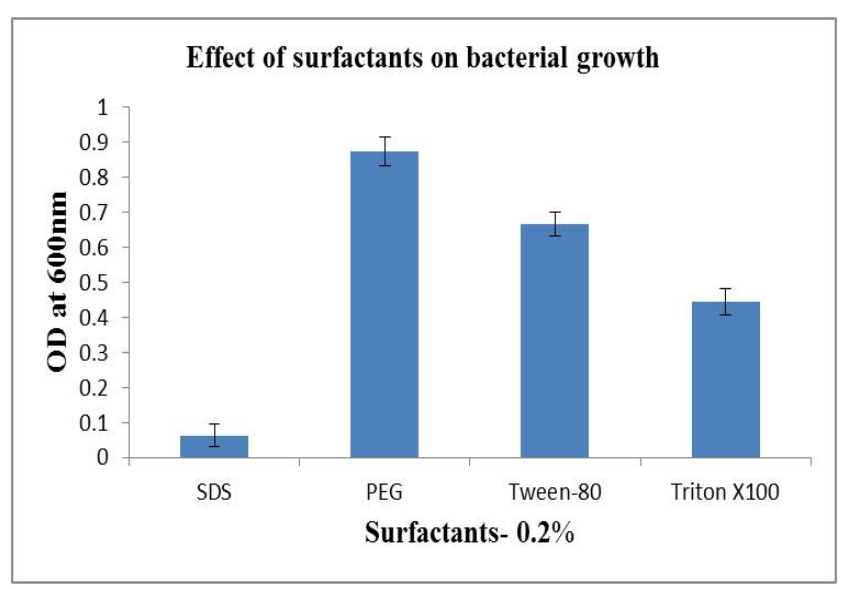

Figure 7. Effect of surfactants

\section{Discussion}

In the present study, the 16S rRNA gene sequences of the isolates had been submitted to the NCBI Genbank and accession number Klebsiella pneumoniae ku215681. Similarly, the B3 -72 strains of Geobacillusthermodenitrificans, isolated from a shallow, marine vent of Vulcano Island. The screened exopolysaccharide producing bacteria from french spoiled cidars allowed to isolate a ropy bacterium belonging to the $B$. Licheniformis species. Strains of B. Licheniformis are also common in foods including natural agricultural cereals [14, $15]$.

In the present study, the maximum EPS production was recorded at $\mathrm{pH} 7.00(1.58 \pm 0.0096)$ and Minimum EPS production was recorded at $\mathrm{pH} 3.00(0.879 \pm 0.0141)$. Likewise Liu et al [8] to observe that the optimal culture media were determined at $\mathrm{pH}$ 7.0. The optimal culture medium constituents were determined as follows: $30 \mathrm{~g} / \mathrm{L}$ sucrose, $3.0 \mathrm{~g} / \mathrm{L}$ soybean meal, $0.25 \mathrm{~g} / \mathrm{L} \mathrm{MgSO}_{4}, 1.5 \mathrm{~g} / \mathrm{L}$ $\mathrm{K}_{2} \mathrm{HPO}_{4}, 0.5 \mathrm{~g} / \mathrm{L} \mathrm{KH}_{2} \mathrm{PO}_{4}, 0.03 \mathrm{~g} / \mathrm{L} \mathrm{ZnSO}_{4}$ and $0.01 \mathrm{~g} / \mathrm{L}$ $\mathrm{FeSO}_{4}$. The optimum parameters for the liquid fermentation were as follows: temperature, $25^{\circ} \mathrm{C}$; cultivation time, 6days; initial $\mathrm{pH}, 8.0$; volume of medium, $150 \mathrm{~mL}$; and rotary speed, $180 \mathrm{rpm}$. GREP content and dry cell weight in optimized conditions were $540.1 \pm 15.9 \mathrm{mg} / \mathrm{L}$ and $8.2 \pm 0.3 \mathrm{~g} / \mathrm{L}$, respectively. GREP content under the optimized conditions was 2.5 times than that under the basic culture medium and initial conditions.

In the present study, the maximum EPS production was obtained at $30^{\circ} \mathrm{C}(1.661 \pm 0.028)$. Similarly Sivakumaret al. [16] stated that the different temperature $\left(25-50{ }^{0} \mathrm{C}\right), \mathrm{pH}$ (5.0-7.5) and $\mathrm{NaCl}_{2}$ concentrations $(0-4 \%)$ were analyzed in MRS broth. The optimal temperature for cell growth and EPS production were $35^{\circ} \mathrm{C}$ with the corresponding cell growth (OD-1.333 $\pm 0.02,1.335 \pm 0.05$ and $1.358 \pm 0.02)$ and EPS $(\mathrm{g} / \mathrm{L})$ production $(7.8 \pm 0.29,7.9 \pm 0.34$ and $8.1 \pm$ 0.27) reported the maximum EPS production by Lactobacillus plantarum MTCC 9510 at $35^{\circ} \mathrm{C}$.

In the present study, the carbon source on EPS production by Klebsiella pneumoniae KU215681after 72 hours incubation at $30^{\circ} \mathrm{C}$. Here the maximum EPS production was observed in Jaggery (1.37 \pm 0.003$)$ supplemented medium. Vijayabaskaret al. [17] reported that maximum EPS production by L. plantarum MTCC 9510 was observed in presence of lactose (40 g L_1). Growth and EPS production by lactic acid bacteria was also enhanced by nitrogen sources. Shankar et al. [13]. The effect of nitrogen sources on EPS production by $S$. phocae showed that yeast extract was most effective than other tested nitrogen sources. This may be due to the presence of larger quantities of free amino acids, short peptides and more growth factors in yeast extract. Among the various concentration, yeast extract at $20 \mathrm{~g} \mathrm{~L}^{-1}$ showed maximum EPS $\left(12.14 \pm 0.31 \mathrm{~g} \mathrm{~L}^{-1}\right)$ production. Yeast extract was reported to be the most efficient nitrogen source, which greatly enhanced the EPS production by $L$. plantarum MTCC 9510 observed maximum EPS production was high in the presence of yeast extract with Paenibacillus polymyca EJS-3 [16, 17].

In the present study, the effect of different nitrogen sources on EPS production after 72 hours of incubation period at $30^{\circ} \mathrm{C}$ showed maximum amount of EPS production on Tryptone (1.56 \pm 0.012) supplemented medium. Correspondingly, the effect of carbon sources on cell growth and EPS production by $S$. phocae was investigated in MRS broth. Among the carbons sources lactose $\left(15 \mathrm{~g} \mathrm{~L}^{-1}\right)$ was found to be best for EPS production. Growth and EPS production by lactic acid bacteria was also enhanced by nitrogen sources [18]. The effect of nitrogen sources on EPS production by $S$. phocae showed that yeast extract was most effective than other tested nitrogen sources. This may be due to the presence of larger quantities of free amino acids, short peptides and more growth factors in yeast extract. Among the various concentration, yeast extract at $20 \mathrm{~g} \mathrm{~L}^{-1}$ showed maximum EPS $\left(12.14 \pm 0.31 \mathrm{~g} \mathrm{~L}^{-1}\right)$ production (Fig.4) Yeast extract was reported to be the most efficient nitrogen source, which greatly enhanced the EPS production by L. plantarum MTCC 9510 observed maximum EPS production was high in the presence of yeast extract by Paenibacillus polymyca EJS-3 [16, 17].

In the present study, the maximum amount of EPS production was observed in Ferric chloride $(1.98 \pm 0.022)$ supplemented medium. Similarly Sivakumar et al. [12] stated that the crude invertase was pre-incubated at $30^{\circ} \mathrm{C}$ for 30 minutes at different concentration of the metal ions prior to standard invertase activity assay with sucrose. Maximum invertase activity of $92.74 \%$ was recorded at calcium chloride. Minimum invertase activity of $23.25 \%$ was recorded at potassium chloride. Partial inhibition of the crude invertase was in the order of $\mathrm{KCl}>\mathrm{MnSo}_{4}>\mathrm{ZnSo}_{4}>$ $\mathrm{NiSO}_{4}>\mathrm{MgSo}_{4}>\mathrm{CoCl}_{2}$

In the present study, the effect of various aminoacids on EPS production after 72 hours of incubation period at $30^{\circ} \mathrm{C}$ showed maximum amount of EPS production observed in Glutamine $(2.13 \pm 0.067)$ supplemented medium. In the same way Chen et al. [15] demonstrated that the effect of amino acids on invertase production by Saccharomyces 
cerevisiae MTCC 170 was studied. Maximum amount of invertase production of $0.26 \pm 0.005 \mathrm{IU} / \mathrm{ml}$ was recorded in methionine and minimum invertase production of $0.03 \pm$ $0.002 \mathrm{IU} / \mathrm{ml}$ was recorded in L-lysine by Saccharomyces cerevisiae MTCC 170.

Among the tested surfactants maximum amount of EPS production was observed in polyethyleneglycol $(0.79 \pm$ 0.043) supplemented medium. Shankar et al. [13] investigated the effect of surfactants on invertase activity by Saccharomyces cerevisiae MK. They determined the effect of various metal ions such as Triton X-100, Tween-20, SDS, polyethyleneglycol and Tween- 80 on the effect of microbial growth and EPS production. They recorded maximum invertase activity of $35.88 \%$ at poly ethylene glycol (1\%) in Saccharomyces cerevisiae MK invertase which was in accordance with the present study.

\section{Conclusions}

A pure bacterial strain capable of producing EPS bacterial strain was isolated and identified as Klebsiellapneumoniae $k u 215681$ by carbohydrate fermentation profile and sequence analysis of $16 \mathrm{~S}$ rRNA. The important parameters had significant positive effects on the EPS production in different nutrients and cultivation conditions.

\section{Conflict of Interest Statement}

The authors declare that they have no conflicting interests.

\section{Acknowledgements}

The authors would like to acknowledge the MRP/5584/15 UGC,SERO for giving financial assistance under minor research project scheme for carryout this work successfully and also thank the Department of Microbiology, Ayya Nadar Janaki Ammal College (Autonomous) Sivakasi 626124, Tamilnadu for providing the facilities to carrying out this work with successful.

\section{REFERENCES}

[1] J.Cerning, C. Bouillanne, M. Landon, M. Desmazeaud. Isolation and characterization of exopolysaccharide from slime forming mesophilic lactic acid bacteria. J. Dairy Sci, Vol.75, 692-699, 1992.

[2] J.H.Joo, J.M. Lim, H.O. Kim, S.W. Kim, J.H. Hwang, J.W. Choi, J.W. Yun. Optimization of submerged culture conditions for exopolysaccharides production in Sarcodonas patus(Berk) TG-3. World J. Microbiol. Biotechnol, Vol.20, 767-773, 2004.

[3] B. Aslim,N.Z. Yuksekdag, Y. Beyatli, N. Mercan.
Exopolysaccharide production by Lactobacillus delbruckii subsp. Bulgaricus and Streptococcus thermophiles strains under different growth conditions. World J Microbiol. Biotechnol. Vol. 21, 673-677, 2005.

[4] I.W. Sutherland. Microbial polysaccharides from Gram-negative bacteria. Int. Dairy J, Vol. 11, 663-674, 2001.

[5] D.Y. Liu, Y. Wang, X.Y. Hu, J.M. Huang, Wang. Preparation, antioxidant and antitumor activities in vitro of different derivatives of levan from endophytic bacterium Paenibacillus polymyxa EJS-3. Carbohydr. Polym, Vol. 71, 180-186, 2008.

[6] A.W. Decho. Microbial biofilms in intertidal systems. An overview Cont. Shelf Res, Vol. 20, 1257-1273, 2000

[7] M. Yasuhiro, K. Yoshimits. Development of a wound dressing composed of hyaluronic acid sponge containing arginine and epidermal growth factor J. Biomat. Sci. Polim. E, Vol. 21, 715-726, 2010.

[8] J. Liu, Luo, H. Ye, Y. Sun, Z. Lu, X. Zeng. In vitro and in vivo antioxidant activity of exopolysaccharides from endophytic bacterium Paenibacillus polymyxa EJS-3. Carbohydrate Polymers, Vol. 82, 1278-1283, 2010.

[9] P. Kanmani, R. Satishkumar, N. Yuvaraj, K.A. Paari, V. Pattukumar, V. Arul. Production and purification of a novel exopolysaccharide from lactic acid bacterium Streptococcus phocae PI80 and its functional characteristics activity in vitro. Bioresource Technology, Vol. 102, 4827-4833, 2011.

[10] B. Ismail, K.M. Nampoothiri. Exopolysaccharide production and prevention of synthesis in starch using encapsulated probiotic Lactobacillus plantarum. Food Technol. Biotechnol, Vol.48, No 4, 484-489, 2010.

[11] V.P. Kodali, S. Das, R. Sen. An exopolysaccharide from a probiotic: Biosynthesis dynamics, composition and emulsifying activity. Food Research International, Vol. 42, 695-699, 2009.

[12] T. Sivakumar, P. Thangamathi, A. Mariashobana, T. Rathimeena, T. Shankar. Optimization of Invertase production using Saccharomyces cerevisiae MTCC 170 under varying cultural conditions. J. Advancement in Medical and Life sciences, Vol. 1, No 2, 1-8, 2014.

[13] T. Shankar, P. Thangamathi, R. Rama, T. Sivakumar. Characterization of Invertase from Saccharomyces cerevisiae MK obtained from toddy sample. J Bioprocessing and Chemical Engineering, Vol. 1, No 2, 1-6, 2014.

[14] S.R. Chowdhurya, R.K. Basaka, R. Senb,B. Adhikari. Characterization and emulsifying property of a carbohydrate polymer produced by Bacillus pumilus UW-02 isolated from waste water irrigated agricultural soil. International Journal of Biological Macromolecules, Vol. 48, 705-712, 2011.

[15] Y. Chen, W. Mao, Y. Yang, X. Teng, W. Zhu, X. Qi, Y. Chen, C. Zhao, Y. Hou, C. Wang, N. Li, Structure and antioxidant activity of an extracellular polysaccharide from coral-associated fungus, Aspergillusversicolor LCJ-5-4. Carbohydrate Polymers, Vol. 1, No 2, 25-32, 2011.

[16] T. Sivakumar, S. Sivasankara Narayani, T. Shankar, P. Vijayabaskar. Optimization of cultural conditions for exopolysaccharides production by Frateuriaaurentia. Inter $\mathrm{J}$ Appl Bio and Pharmaceutical Technol, Vol. 3, No 3, 133-143, 2012. 
[17] P. Vijayabaskar, S. Babinastarlin, T. Shankar, T. Sivakumar, K.T.K. Anandapandian. Quantification and Characterization of Exopolysaccharides from Bacillus subtilis (MTCC 121). Adv. Biological Research, Vol. 5, No 2, 71-76, 2011.
[18] T. Shankar, P. Vijayabaskar, S. Sivasankara Narayani, T. Sivakumar. Screening of Exopolysaccharide producing bacterium Frateuria aurentia from Elephant Dung. Applied Science Reports, Vol. 1, No 3, 105-109, 2014. 